\title{
Towards an unbiased estimate of fluctuations in reef abundance and volume during the Phanerozoic
}

\author{
W. Kiessling \\ Museum of Natural History, Humboldt-University Berlin, Invalidenstr. 43, 10115 Berlin, Germany \\ Received: 17 August 2005 - Published in Biogeosciences Discussions: 22 September 2005 \\ Revised: 5 December 2005 - Accepted: 7 December 2005 - Published: 11 January 2006
}

\begin{abstract}
The globally preserved number and volume of ancient biogenic reefs is strongly biased by two factors: geological history and research intensity. These biases are sufficiently strong to cast doubts on the biological meaning of the recorded raw pattern. Without adjustment, it is hard to reliably identify factors potentially controlling the waxing and waning of this important ecosystem through time. Although it is currently impossible to completely compensate for the biases, I demonstrate here, based on a comprehensive database of ancient reefs, that spatiotemporal heterogeneities of the biases can largely be evened out by: (1) omitting oceanic reef sites and reef sites only known from subsurface exploration; (2) standardizing for economic factors known to affect research intensity; and (3) adjusting for sedimentary cycling processes. The resulting curves of fossil reef abundance and volume appear quite different from the original ones but the patterns of waxing and waning of the time series are not significantly altered and the overall volatility is not reduced. This suggests that both the raw curves and the adjusted curves correctly depict the basic timing of major reef blooms and declines. Nevertheless, the general pattern of the new curves (maximum proliferation in the middle Paleozoic, decline thereafter) is more in line with patterns of global cratonic carbonate sedimentation than the original curves. The adjusted curves should thus be preferred over the original ones for future tests of potential extrinsic controls of Phanerozoic reef development.
\end{abstract}

\section{Introduction}

The bias of the fossil record has repeatedly been emphasized in the last few years. Most studies agree that recorded changes of biodiversity are so strongly governed by changes

Correspondence to: $\mathrm{W}$. Kiessling

(wolfgang.kiessling@ museum.hu-berlin.de) in the quality of the geological record that the biological signal is largely overprinted (Peters and Foote, 2001; Smith, 2001; Crampton et al., 2003). However, little has been done to adjust for this bias in order to achieve biologically more meaningful patterns of diversity through geological time. For biodiversity, large-scale heterogeneities of sampling intensity can be balanced by subsampling techniques based on weighted random draws from the available sampling pool (Alroy et al., 2001; Bush et al., 2004). Equivalent adjustments are more difficult when the unit of sampling is a biological community and the pattern of interest is abundance or productivity rather than diversity. These adjustments, however, are an important prerequisite for meaningful analyses at the ecosystem level.

Here I focus on the abundance $(N)$ and volume $(V)$ of tropical reefs through the Phanerozoic. These patterns provide important proxies of the waxing of waning of a wellconstrained marine ecosystem. Similar to biodiversity, there is no hope to ever gain a reliable number of the true values at any particular time, but the preserved record must be standardized as much as possible.

The goal of this paper is to remove as much bias as possible from the time series of $N$ and $V$ as recorded in a database on Phanerozoic reefs, the so-called PaleoReefs database (Kiessling and Flügel, 2002; http://193.175.236. 205/paleo/, ID=paleo; Password=reefs). Previous analyses of this database have found several significant crosscorrelations between environmental change and changes in reef attributes but failed to detect extrinsic factors determining the waxing and waning of global reef production (Kiessling, 2002). It is possible that intrinsic factors such as biodiversity override the control of environmental factors (Kiessling, 2005a) or the environmental factors are insufficiently resolved. However, it is as well possible that the recorded time series of $N$ and $V$ are just too biased to reflect the true pattern of Phanerozoic reef carbonate production (Kiessling, 2005b). Thus the full appreciation of potential

(C) 2006 Author(s). This work is licensed under a Creative Commons License. 

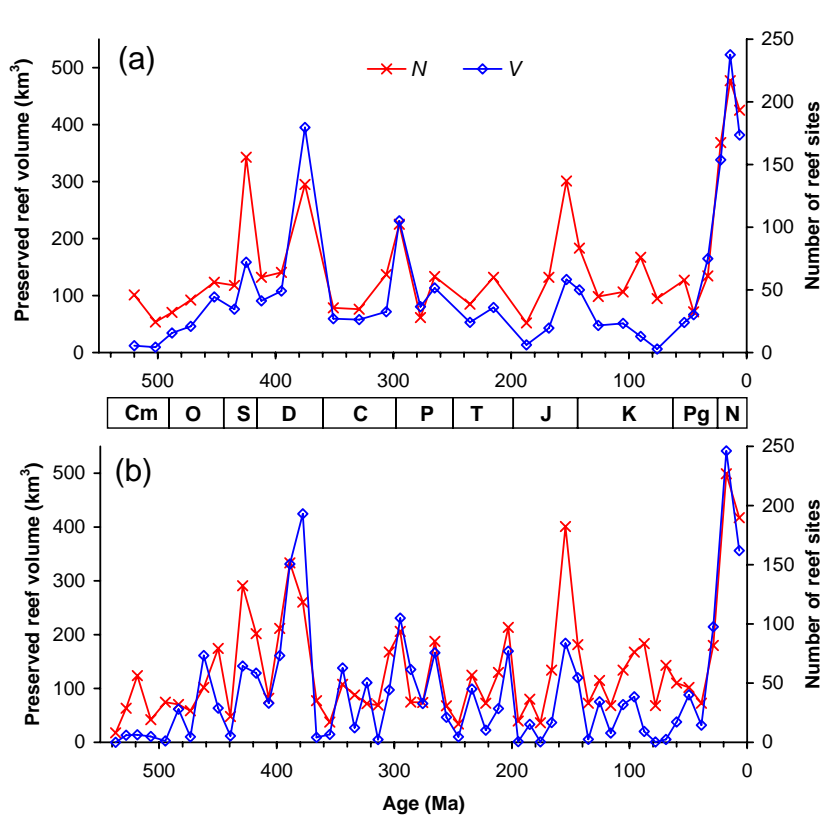

Fig. 1. Time series of the recorded number of reef sites ( $N$, red line) and calculated total preserved reef volume $(V$, blue line) through the Phanerozoic based on the PaleoReefs database. Raw values, normalized to $10 \mathrm{Myr}$ intervals. Bold letter codes indicate geological periods: $\mathrm{Cm}$, Cambrian; O, Ordovician; S, Silurian; D, Devonian; C, Carboniferous; P, Permian; T, Triassic; J, Jurassic; K, Cretaceous, Pg, Paleogene; N, Neogene. (a) Data resolved to supersequences. (b) Data resolved to $10 \mathrm{Myr}$ intervals.

physico-chemical controls on reef ecosystems through time will only be possible when all potential biases are removed.

\section{Database and methods}

The analyses are based on a comprehensive database of Phanerozoic reefs (Kiessling and Flügel, 2002) currently comprising 3367 entries. This database contains information on paleogeographic, paleontological, geometrical, and petrographical attributes on mostly pre-Pleistocene Phanerozoic reef sites, where a site lumps data from reefs of the same age and environmental setting within an area of roughly $350 \mathrm{~km}^{2}$. Previous analyses have detailed the patterns of reef abundance and calcium carbonate $\left(\mathrm{CaCO}_{3}\right)$ production through time (Kiessling et al., 1999, 2000; Kiessling, 2002) but potential biases in these patterns were always a matter of concern (Kiessling et al., 1999; Kiessling, 2002, 2005b). The method of calculating the preserved volume of reefs is as in Kiessling et al. (2000), except that I focus on preserved volume (= net accumulation of calcium carbonate) rather than estimates of gross $\mathrm{CaCO}_{3}$ production. This method assumes simple reef geometries and gives very conservative estimates of preserved reef volume. The volume is calculated from just the measured portion of reported reef sites and does not consider reconstructions of reef tracts. Although it is obvious that the calculated volumes are at least one order of magnitude lower than presumed true volumes, there is currently no sound way to extrapolate these measured values using estimates of extensions of reef tracts.

The recorded pattern of the number of reef sites and their cumulative volume through time (Fig. 1) is a function of true fluctuations and the sum of distorting factors. The severity of these distortions has recently been quantified (Kiessling, 2005b), focusing on the effects of habitat area, the number of oceanic reefs, reservoir potential, and socioeconomic factors. Socioeconomic factors, most importantly economic productivity per unit area, were identified as introducing the most severe bias in the recorded number and volume of ancient reefs, but the other factors are also likely to distort the biological signal. What was missing in the previous analysis was an approach towards compensation of these biases, in order to reconstruct a more realistic time series.

Here I present methods and results of an adjustment in four logical steps. The first step is an omission of reef sites with low preservation potential on geological time scales. The second step smoothens out artifactual heterogeneities of sampling intensity by excluding reefs only known from subsurface exploration. In the third step, perhaps the most controversial, I try to adjust for the effects of heterogeneous spatial sampling due to differences in gross domestic product between countries. The fourth and final step compensates the long-term trends of sediment preservation in the geological record.

Because temporal resolution does matter, I report raw data and adjustments for two different sample resolutions. The first sample resolution is based on supersequences defined by semi-global unconformities (with an average duration of $17 \mathrm{Myr}$ ); the second is based on time intervals (bins) of roughly ten million years (Myr) duration, but adheres to traditional paleontologically defined boundaries (Kiessling, 2005a). A complication exists due to imprecisely dated reefs, which cannot be assigned with confidence to a particular bin. This is not a problem for supersequences, because only reefs confidently assignable to a supersequence were included in the database. However, with finer temporal resolution, reef sites become more common, which cannot be assigned to a single bin. There are several options to handle this problem: one can simply omit those imprecisely dated reefs, or one can assign them to all bins spanning the time of imprecision. In either case, the total counts at the finer sample resolution will differ from the total at the coarser resolution. To keep the total counts constant (which is necessary for some adjustments), I applied a random bin assignment for imprecisely dated reefs.

Both time series consist of bins with slightly unequal durations. Therefore all numbers have been normalized to $10 \mathrm{Myr}$ intervals following the time scale of Gradstein et al. (2004). Changes in the time series after manipulation are recorded by overall similarity (correlation), changes in standard deviation 
of the total time series and changes in volatility (volat) of the complete time series:

volat $=\operatorname{std}\left(\ln \left(\frac{(\mathrm{N}, \mathrm{V})_{t}}{(\mathrm{~N}, \mathrm{~V})_{t-1}}\right)\right)$

where $(N, V)$ is the recorded number of reef sites $(N)$ or reef volume $(V)$ in a bin $t$ and in the previous bin $t-1$, and $s t d$ stands for the standard deviation of the natural logarithm (ln)-transformed quotients. Following standard methods used in volatility estimation of financial time series (http://www.riskglossary.com/link/volatility.htm), I apply a ln-transformed quotient rather than simple first differences.

\subsection{Excluding oceanic reefs}

Oceanic atolls are important reef sites today. A survey of Reefbase (http://www.reefbase.org), a database on modern tropical coral reefs, suggests that $37 \pm 2 \%$ of all modern tropical coral reefs are situated in oceanic regions (Kiessling, 2005b). Due to subduction processes associated with plate tectonics, oceanic reef sites have little chance of a lasting geological record, especially the smaller volcanic islands and seamounts (Cloos, 1993), which are important reef sites today (Vecsei, 2000). The higher probability of preservation of younger oceanic reef sites introduces a severe bias towards higher reef numbers in more recent times. In the PaleoReef database, $10 \%$ of all Miocene reefs are from oceanic sites, whereas just $5 \%$ of all Late Cretaceous reef sites are oceanic and there are virtually none prior to the Jurassic. There are obviously some exceptions to the long-term term decline of oceanic reef sites. The richness of late Early Cretaceous seamounts (guyots today) in the Pacific Ocean, probably related to a mid-Cretaceous superplume (Larson, 1991), provided abundant oceanic habitat area for reef growth and carbonate platform development (Wilson et al., 1998). In the Aptian and Albian stages (125-100 Myr before present) roughly $20 \%$ of all documented reef sites are from Pacific guyots.

Thus the original proportion of oceanic reef sites obviously varied through time and a reliable global adjustment cannot be made until we have better constraints on the secular variations of seamount formation rates. Although some indirect measures are being developed (e.g., correlations with sea-floor spreading rates, Behn et al., 2004), the prediction of original pre-Jurassic oceanic habitat area (and by inference reef abundance) will perhaps always remain impossible. Nevertheless an adjustment has to made to at least reduce the bias. Here I omitted all oceanic reefs to adjust for the overrepresentation of oceanic reefs in younger times. This adjustment implies that the resulting curve is valid only for reefs on continental crust.

\subsection{Excluding subsurface data}

The PaleoReef database contains many reefs known only from subsurface exploration, either from drilling or seismic data (607 out of 3266 non-oceanic reef sites, or $18.6 \pm 1.3 \%$ ). While it is beneficial to have data from the subsurface, where paleontologically relevant information is usually scarce, the heterogeneous temporal distribution of the proportion of subsurface reefs suggests a strong bias. The proportion of reefs with hydrocarbon reservoir potential and the proportion of subsurface reefs are significantly cross-correlated ( $R=0.76, P<0.001$ for first differences), which suggests that the recorded number of subsurface reefs is strongly controlled by economic interest. This means that the true number of reefs will be greatly underestimated when reefs have no reservoir potential and are thus rarely explored by drilling. Furthermore subsurface reefs tend to be larger in thickness, either due to different methods in estimating reef geometries or due to the fact that only larger reefs are recorded by seismic exploration. This imposes a strong bias on the calculations of preserved reef volume. For these reasons complete removal is the best way to adjust for the bias introduced by subsurface reefs. This adjustment may not balance all bias introduced by the economic interest in reefs as hydrocarbon reservoirs. Exposed reefs also tend to be studied more intensely, when they can be used as models for subsurface reservoirs. Although, there is no way to estimate this exploration bias quantitatively, it may not be that strong because reefs from bins without significant hydrocarbon accumulations are also being used as reservoir analogues (e.g., Antonellini and Mollema, 2000 for a Triassic example).

On the other hand, burial and failed uplift may unfairly underestimate the global number of reef sites relative to other bins when most of the formerly buried reef sites became exposed by tectonic processes. The Cambrian of cratonic North America and the Miocene in the Indo-Pacific region are good examples for an elevated proportion of buried sediments with reefs, whereas most of the Tethyan Triassic reefs were exposed by Alpine-Himalayan orogeny. Reliable estimates of subsurface and outcrop area of sedimentary rocks would be needed to get a better resolved measure of true fluctuations of subsurface reef abundance. At this point, the strong crosscorrelation between reservoir potential and subsurface reefs dictates the exclusion of subsurface reefs to approach a more unbiased pattern.

\subsection{Adjustment for variations in gross domestic product}

While the number of subsurface reefs is controlled by economic interest, the number of recorded reefs in general may also be governed by economy. I have previously demonstrated that the number of reef sites and their cumulative volume described from each country is strongly dependent on its gross domestic product (GDP), especially when normalized by land area (Kiessling, 2005b). More reefs are known from countries with a high GDP density (GDP per unit area) than from countries where the GDP density is low. It is possible the PaleoReef database does not contain all the global data because it is focusing on international literature. However, 
the focus of data gathering was always on a maximum geographic distribution of the data and more than $50 \%$ of the reef data are from sources not covered by Journal Citation Reports published by Thomson ISI. In spite of a number of additional factors that affect the number and volume of documented fossil reefs, the strong correlation suggests that economy or some correlate of economy severely biases the record of reefs, at least as reflected by entries in the PaleoReefs database (Kiessling, 2005b). Although the mobility of geoscientists from rich countries is increasing, the long history of research within rich countries is far from being made up. Additionally, even with increased mobility, biogeologists appear to favor countries with relatively high GDP density, perhaps owing to constraints on infrastructure, safety, and bureaucracy.

The quantitative correlation between GDP density and reef density per country can also be seen qualitatively. For example, the widespread Late Jurassic (mostly Oxfordian) sponge-microbial reefs of Europe are apparently much more common in Germany (15 detailed records of this reef type) than in Poland (four detailed records) although summary maps (e.g., Leinfelder et al., 1996) indicate a very similar extent of the so-called spongiolithic facies in both countries. The similar difference in GDP density (Germany, 7.75 million dollars per $\mathrm{km}^{2}$; Poland 0.55 million dollars per $\mathrm{km}^{2}$; data as of 2002 in 1995 US-\$) underlines that the bias is correlated with the GDP density. Another example is the apparent truncation of a Middle Miocene reef tract along the Red Sea Coast at the Egypt/Sudan border. Egyptian coral reefs have received considerable attention from both local and foreign biogeologists and eleven reefs are described in detail, but there is only one detailed account of the same reef tract in the much poorer Sudan with just two reef sites described in some detail (Sestini, 1965).

Kiessling (2005b) found that $54 \%$ of the variance in lntransformed reef density (number of reefs per unit area) can be explained by variations in In GDP density (GDP per unit area) between countries. Because this former study has included oceanic and subsurface reefs, the correlation values of Kiessling (2005b) cannot be used directly for this study. A new analysis of the reduced PaleoReefs database (oceanic and subsurface reefs excluded) was thus performed, based on a threshold of at least five reef sites per country (78 countries meet this criterion). This threshold was chosen to reduce statistical noise. With a lower quota, changes in reef abundance are increasingly due to chance, as numbers are then just based on one or two studies (references). One should note, however, that the basic results remain the same when all reef-bearing countries $(=111)$ are included in the analysis.

The Pearson correlation between ln GDP density and ln density of reef sites is $0.665(P<0.001)$. The variance explained by $\ln$ GDP density is thus $44 \%$, which is lower than in the full dataset, probably due to the reduction of economic bias by exclusion of subsurface reef sites. Between ln GDP density and $\ln$ reef volume density, the correlation is $R=0.304$ ( $P=0.007)$. The much stronger correlation with numbers than with volumes is probably due to the overestimation of reef sizes in less developed countries. Judging from my own experience with entering data into the PaleoReefs database, the most likely reason for the overestimation of reef sizes is the inclusion of extra-reefal carbonates into estimates of reef sizes. One specific example comes from the Jurassic Esfandiar Limestone in Iran, which has been qualified as a several hundred meters thick reefal limestone (algal reef) in older local surveys (Stöcklin et al., 1965), when there is nothing but small microbial biostromes and bioherms in the region (F. Fürsich, personal communication, 2003). Nevertheless, a significant bias of GDP is evident both for numbers and volume. The correlation coefficients are somewhat higher for Spearman rank correlations $(R=0.688$ and $R=0.363$, respectively), but since the data are nearly normally distributed on a ln scale, the Pearson correlations are used for adjustment.

For all reefs, the adjustment is relatively straightforward. There are basically two ways to adjust for the GDP density effect on reef density. One uses the regression equation and the other applies the correlation coefficient. I have used the most conservative method (that is, the one providing the lowest correction factor) for $N$ and $V$. To correct for $N$ in each country where reefs are preserved, I have first extracted the equation of the regression analysis:

$\ln \left(\frac{\mathrm{N}}{\text { area }}\right)=1.69+0.46 \ln \left(\frac{\mathrm{GDP}}{\text { area }}\right)$

where $N$ is the number of reef sites within the country, area is the land area of the country in million square kilometers, and GDP is the gross domestic product of the country in billion dollars. From this, one can calculate the expected number of reef sites $\left(N_{\text {exd }}\right)$, when GDP density (GDP_area) would be a perfect predictor of reef density:

$N_{\text {exd }}=\operatorname{area} \times e^{1.69+0.46 \ln \left(\mathrm{GDP} \_ \text {area }\right)}$

The residuals (res) of the regression were factored in to achieve a more realistic prediction of $N$ at a given GDP density:

$N_{\mathrm{GDP}}=\operatorname{area} \times e^{1.69+0.46 \ln \left(\mathrm{GDP} \_ \text {area }\right)+\text { res }}$

With this, the expected number of reef sites $\left(N_{\mathrm{GDP}}\right)$ can be calculated for any GDP density and can be both interpolated and extrapolated. Here I use the ln GDP density of Romania (5.07 as of 2002) as the level of adjustment, which is closest to the average ln-transformed GDP density of all countries with reefs. The least and most explored countries can then be identified by the maximum differences between predicted and observed values (Table 1). The quotient of $N_{\text {GDP }}$ and observed $N$ in each country can be used to derive a correction factor for each country $\left(N_{\text {fact }}\right)$, which can also be applied to adjustments within bins (see below). 
Table 1. Ten most under-explored and five most over-explored countries measured by the number of reefs predicted to be found if GDP density is to the level of Romania. $N_{O}=$ observed values after subtraction of oceanic and subsurface reef sites. Predicted values $\left(N_{\mathrm{GDP}}\right)$ calculated according to Eq. (4). Difference $N=$ difference between predicted and observed, $N_{\text {fact }}=$ quotient of predicted/observed. Data on land area are from the CIA World Factbook at http://www.cia.gov/cia/publications/factbook/ and GDP data are from International Energy Annual at http://www.eia.doe.gov/emeu/iea/popgdp.html (both accessed in January 2005).

\begin{tabular}{lcccccc}
\hline Country & Land area $\left(10^{6} \mathrm{~km}^{2}\right)$ & GDP $2002\left(10^{9}\right.$ US-\$) & $N_{\mathrm{O}}$ & $N_{\text {GDP }}$ & Difference $N$ & $N_{\text {fact }}$ \\
\hline Russia & 16.996 & 381.6 & 246 & 605 & 359 & 2.46 \\
Mongolia & 1.555 & 1.1 & 22 & 266 & 244 & 12.11 \\
Afghanistan & 0.648 & 2.4 & 19 & 107 & 88 & 5.64 \\
Canada & 9.094 & 753.4 & 250 & 336 & 86 & 1.34 \\
Kazakhstan & 2.670 & 24 & 28 & 105 & 77 & 3.74 \\
Somalia & 0.638 & 1.1 & 9 & 72 & 63 & 8.02 \\
Tajikistan & 0.143 & 0.8 & 14 & 66 & 52 & 4.69 \\
Tanzania & 0.886 & 7.2 & 10 & 39 & 29 & 3.91 \\
Algeria & 2.382 & 55.2 & 17 & 41 & 24 & 2.44 \\
Australia & 7.618 & 468.7 & 44 & 68 & 24 & 1.54 \\
Germany & 0.349 & 2708.1 & 84 & 14 & -70 & 0.17 \\
Spain & 0.500 & 738.6 & 110 & 39 & -71 & 0.36 \\
France & 0.546 & 1831.5 & 95 & 23 & -72 & 0.25 \\
Italy & 0.294 & 1234.3 & 123 & 27 & -96 & 0.22 \\
United States & 9.162 & 9234.1 & 323 & 138 & -185 & 0.43 \\
\hline
\end{tabular}

For reef volumes, the regression analysis can be transformed the same way as in Eqs. (2-4) resulting in:

$\mathrm{V}_{\mathrm{GDP}}=\operatorname{area} \times \mathrm{e}^{0.19+0.42 \ln \left(\mathrm{GDP}_{-} \text {area }\right)+\text { res }}$

However, because the correlation coefficient is low, it is more conservative to calculate the expected reef volume for a given GDP density by:

$\mathrm{V}_{\mathrm{GDP} 2}=\mathrm{V}_{\mathrm{O}} \times \mathrm{e}^{\mathrm{R}\left(\Delta\left(\ln \left(\mathrm{GDP} \_ \text {area }\right)\right)\right)}$

where $V_{\mathrm{GDP} 2}$ is the GDP-adjusted reef volume in a country, $V_{\mathrm{O}}$ is the observed reef volume, $R$ is the correlation factor derived from all reefs and countries $(=0.304)$ and $\Delta\left(\ln \left(\mathrm{GDP}_{\mathrm{area}}\right)\right)$ is the difference between the level of adjustment (ln GDP density of Romania) and the ln GDP density of the country in question. The term $\exp (R \times \Delta((\ln ($ GDP_area $)))$ is used as the correction factor of $V$ for each country ( $V_{\text {fact }}$ ). Due to the higher correlation coefficient, applying Eq. (6) to $N$ would result in higher values of $N_{\text {fact }}$ and hence Eq. (4) is preferred for the adjustment of $N$.

The ranking of the least and most explored countries in terms of recorded reef volume (Table 2) is similar to the one for reef abundance. Not surprisingly, the five least explored countries are fairly large relative to their GDP. Russia, Mongolia, Afghanistan, Canada and Kazakhstan are in the top five least explored countries by both adjustments for $N$ and $V$, and Germany, Italy and the United States are always in the top five most explored countries. Owing to its very low GDP density, Mongolia has particularly high values of both $N_{\text {fact }}$ and $V_{\text {fact }}$.
Similarly to the global pool of data, it is reasonable to assume that the global number of reefs is overestimated with respect to other bins when the majority of reefs from a particular bin are known from countries with a high GDP density, whereas the number of reefs is underestimated when most of the reefs are known from countries with a low GDP density. Indeed, the basic correlation between GDP density and reef density per country is also evident for some individual bins, although correlation coefficients are usually smaller. An analysis of the six richest supersequences ( $S$, each with at least 125 reef sites) suggests an increasing dependency through time. Correlations are insignificant in the Ordovician $(S 5)$ and Silurian (S7), significant in the Devonian and Triassic ( $S 10: R=0.50, P=0.015 ; S 18: R=0.44, P=0.012)$ and highly significant in the Jurassic and Miocene ( $S 21: R=0.57$, $P<0.001 ; S 31: R=0.48 ; P=0.004)$. Although this could mean that the bias of economy is less prevalent in the early Paleozoic (e.g., countries with a low GDP density are better sampled), it could as well be due to random effects of lower sample sizes. The lower correlations can also be explained by the fact that most of the Paleozoic reefs are recorded from sites in large countries with a relatively low GDP density (mostly listed in Table 1). Thus it is straightforward to apply the correction coefficients ( $N_{\text {fact }}$ and $\left.V_{\text {fact }}\right)$ derived from the total (=Phanerozoic) data pool to individual bins.

This is done by multiplying the raw values of $N$ and $V$ recorded in a bin by $N_{\text {fact }}$ and $V_{\text {fact }}$ for each country and then summing the results up to achieve a GDP-adjusted estimate of the grand total in this bin. For example, in $S 9$ (Emsian-Eifelian supersequence) there are eight exposed reef 
Table 2. Ten most under-explored and five most over-explored countries measured by the volume of reefs predicted to be found if GDP density is to the level of Romania. $V_{\mathrm{O}}=$ observed values after subtraction of oceanic and subsurface reef sites. Expected values $\left(V_{\mathrm{GDP}}\right.$ and $V_{\mathrm{GDP} 2}$ ) calculated according to Eqs. (5) and (6), respectively. Difference $V=$ difference between predicted and observed, $V_{\text {fact }}=$ quotient of $V_{\mathrm{GDP} 2} / V_{O}$.

\begin{tabular}{lcccccc}
\hline Country & $V_{\mathrm{O}}\left(\mathrm{km}^{3}\right)$ & $V_{\mathrm{GDP}}$ & Difference $V_{\mathrm{GDP}}$ & $V_{\mathrm{GDP} 2}$ & Difference $V_{\mathrm{GDP} 2}$ & $V_{\text {fact }}$ \\
\hline Russia & 352.521 & 801.245 & 448.724 & 639.669 & 287.148 & 1.815 \\
Canada & 386.857 & 508.040 & 121.183 & 471.376 & 84.519 & 1.218 \\
Kazakhstan & 60.455 & 201.826 & 141.371 & 144.659 & 84.204 & 2.393 \\
Mongolia & 12.224 & 118.882 & 106.658 & 63.503 & 51.279 & 5.195 \\
Afghanistan & 18.937 & 92.256 & 73.319 & 59.392 & 40.455 & 3.136 \\
Tajikistan & 16.332 & 66.686 & 50.354 & 45.219 & 28.887 & 2.769 \\
Madagascar & 12.004 & 47.700 & 35.696 & 32.536 & 20.532 & 2.710 \\
Australia & 57.949 & 86.445 & 28.496 & 77.352 & 19.403 & 1.335 \\
China & 219.351 & 240.099 & 20.748 & 233.811 & 14.460 & 1.066 \\
Iraq & 12.002 & 32.209 & 20.207 & 24.594 & 12.592 & 2.049 \\
Germany & 53.128 & 10.321 & -42.807 & 16.283 & -36.845 & 0.306 \\
Ireland & 78.665 & 28.817 & -49.848 & 38.040 & -40.625 & 0.484 \\
Italy & 90.096 & 22.703 & -67.393 & 33.341 & -56.755 & 0.370 \\
Austria & 97.782 & 27.143 & -70.639 & 38.806 & -58.976 & 0.397 \\
United States & 343.884 & 158.865 & -185.019 & 195.959 & -147.925 & 0.570 \\
\hline
\end{tabular}

Table 3. Empirical decay constants $\left(k\right.$, in $\left.\mathrm{Myr}^{-1}\right)$ for Phanerozoic reefs.

\begin{tabular}{lcccc}
\hline & \multicolumn{2}{c}{ Supersequences } & \multicolumn{2}{c}{$10 \mathrm{Myr}$ intervals } \\
& $N$ & $V$ & $N$ & $V$ \\
\hline Raw data & 0.0012 & 0.0016 & 0.0013 & 0.002 \\
Oceanic and subsurface reef excluded & 0.0006 & -0.0014 & 0.0008 & 0.0007 \\
GDP-adjusted data & -0.0005 & -0.0019 & -0.0004 & -0.0002 \\
\hline
\end{tabular}

sites recorded from Mongolia and 13 from the United States. Standardizing $N$ to the GDP density of Romania, that is, applying $N_{\text {fact }}$ as listed in Table 1, expands the number of reefs in Mongolia to $12.11 \times 8=96.9$ reefs and reduces the number of reefs in the United States to $0.43 \times 13=5$.6. If these two countries were the only ones with a reefal record in this supersequence (which they are not), the total GDP-adjusted number would rise to 102.5 as compared with 21 in the raw data.

This method implies that adjustments are only being made for countries in which reefs have actually been recorded. With good knowledge of the paleogeology of all bins, adjustments could also be applied for countries without any record of reefs at a particular time.

\subsection{Compensation of sediment cycling}

The amount of sediment preserved with time is well known to fit an exponential decay curve (Gregor, 1985; Wilkinson and Walker, 1989; Wold and Hay, 1990, 1993). Although the fit to actual data is quite poor for sedimentary carbonates in general (Morse and Mackenzie, 1990; Mackenzie and Morse, 1992) and in reefs in particular (Kiessling, 2002), there is no reason to assume that the basic principles of sediment decay through time do not apply for $\mathrm{CaCO}_{3}$. An exponential decay can thus be assumed as a first approximation.

$(N, V)_{R}=(N, V)_{P} \times e^{k t}$

where $(N, V)_{R}=$ reconstructed number of reef sites or reef volume; $(N, V)_{P}=$ preserved number of reef sites or reef volume; $k=$ decay constant; $t=$ midpoint of bin in Myr.

The empirically derived decay constants for the raw data are suspiciously low for reef numbers and even negative for all GDP-adjusted data (Table 3). This is a common observation when looking at carbonate preservation through the Phanerozoic. The Phanerozoic shift of $\mathrm{CaCO}_{3}$ production to the open ocean (Wilkinson and Walker, 1989) and the drift of shelf areas to latitudes unsuitable for prolific carbonate sedimentation has resulted in the paradox of negative decay constants for shallow water carbonates (Walker et al., 2002). Just as systematic long-term shifts in the carbonate reservoir size obscure the reliable identification of decay constants for 

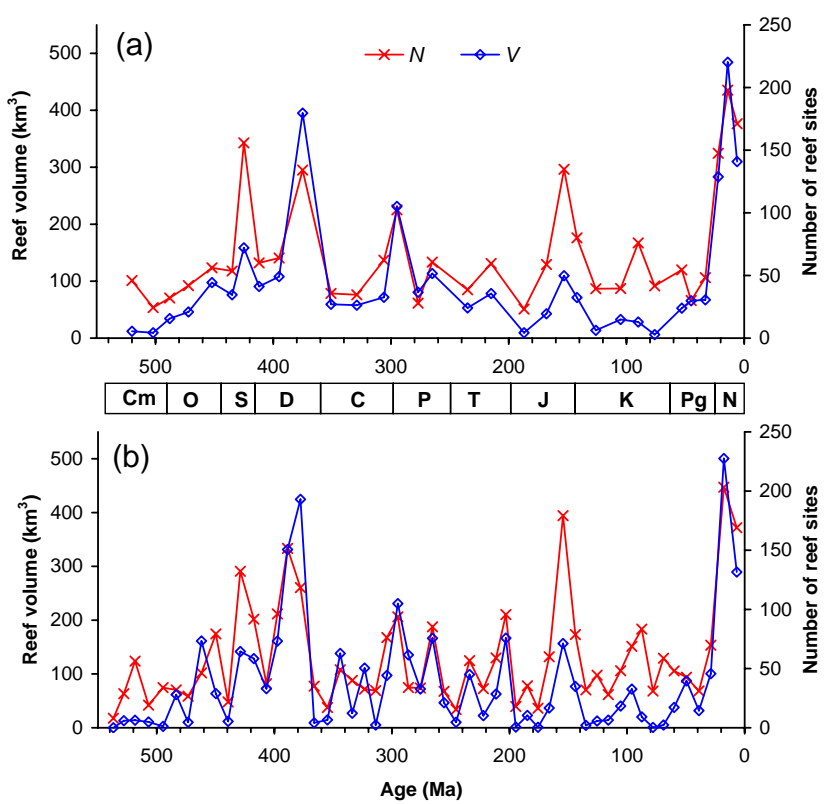

Fig. 2. Time series of the recorded number of reef sites and total reef volume after removal of oceanic reef sites. (a) Data resolved to supersequences. (b) Data resolved to $10 \mathrm{Myr}$ intervals. See the legend of Fig. 1 for additional information.

sedimentary carbonates in general, true fluctuations in reef proliferation hinder the empirical determination of a decay constant for the erosional destruction of reefs. The only benefit from the experimental determination of decay constants in reefs is to show that these are comparable for numbers and volumes (Table 3). It may thus be permitted to apply a single decay constant for both measures, which however has to be derived from an independent data source.

I derived a decay constant from the known mass/age distribution of all Phanerozoic sediments. Hay and Wold (1990) have compiled information of earlier work (Ronov et al., 1980; Budyko et al., 1987) and normalized the data to $10 \mathrm{Myr}$ bins. I have extracted their data for the mass/age distribution of sediments on the continents and passive continental margins, modeled the data into the time scale used in this study and fitted an exponential decay curve. The resulting decay constant of $0.0014 \mathrm{Myr}^{-1}$ is used as a first approximation of reef survival rates (both for $V$ and $N$ ) through the sedimentary record.

Apart from true fluctuations in reef proliferation, the imperfect fit of decay curves can also be explained by cyclic changes in weathering intensity due to large-scale sea level fluctuations, which in turn are controlled by plate tectonic processes (Mackenzie and Morse, 1992). Global phases of plate assembly and disassembly are known to alter sedimentation and erosion regimes at global scales (Ronov, 1994). A potential proxy tracing these changes is the percentage of continental area covered by seawater, which is a function of eustatic sea level and hypsometry. Empirical evidence con-
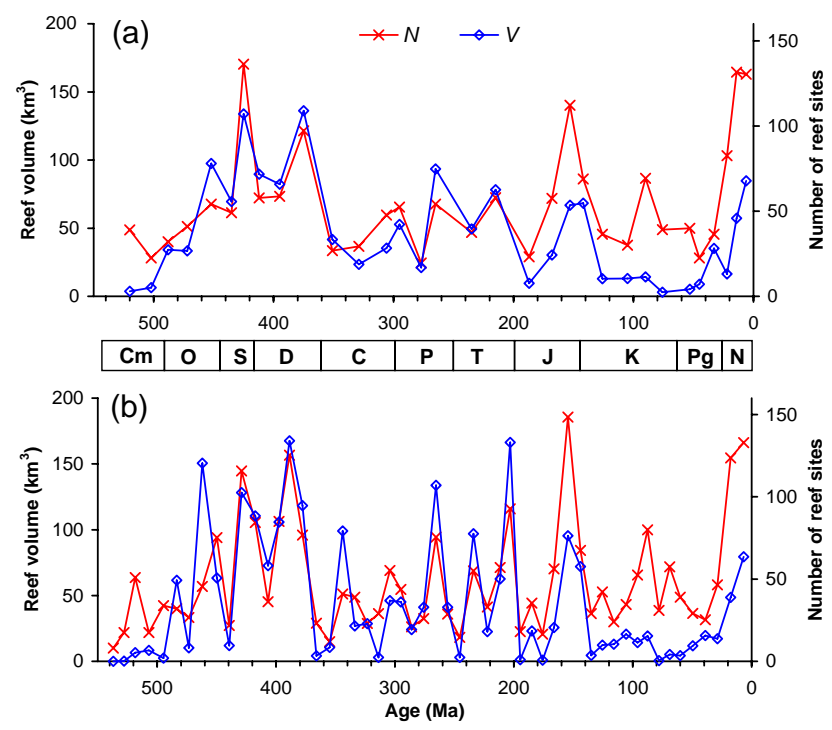

Fig. 3. Time series of the recorded number of reef sites $(N)$ and total reef volume $(V)$ after removal of oceanic and subsurface reef sites. (a) Data resolved to supersequences. (b) Data resolved to $10 \mathrm{Myr}$ intervals. See the legend of Fig. 1 for additional information.

firms that changes in continental flooding are indeed significantly cross-correlated with changes in preserved reef abundance (Kiessling, 2002). Therefore, I have previously suggested introducing an additional factor to adjust for the effect of continental flooding (Kiessling, 2002).

However, continental flooding or its inverse, continental freeboard, acts in two ways on the preservation of ancient reefs. The first way is the control of flooding on habitat area. As tropical reefs have a strong preference for shallow water habitats, the reduction of shelf area by a relative sea level fall may considerably lower the available habitat area and thereby global reef carbonate production (Kleypas, 1997). Changes in habitat area certainly influence the $\mathrm{CaCO}_{3}$ production of reefs, but they do not strictly represent a sampling bias. The second way is the effect of continental flooding on the volume of preserved sediment. Increases in continental freeboard are associated with erosion of older sediments. While at relatively fine temporal scales (stage level and finer) the biasing effect of low sea level is suspected to occur at a temporal lag (the backward and forward smearing effects; Foote, 2001), it is reasonable to assume that over longer bins, the erosion effect will be strongest within a bin. Mackenzie and Morse (1992) have previously noted a good match between declining rates of carbonate preservation and orogenic cycles, with survival rates declining when approaching the Slossian (Sloss, 1963, 1976) megasequence boundaries.

At this point it is hard to decide which of the two effects will more strongly influence the preserved number and volume of reefs. In any case, a simple adjustment for continental flooding will always result in a mixed signal. Therefore, proxies of actual weathering rates are required. It is 
(a)

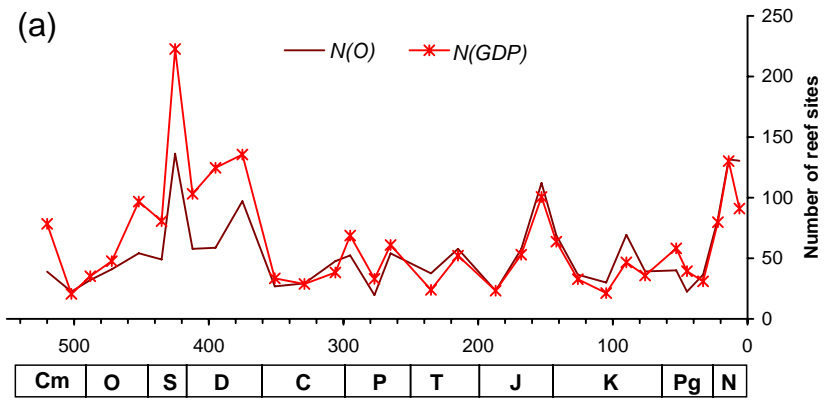

(b)

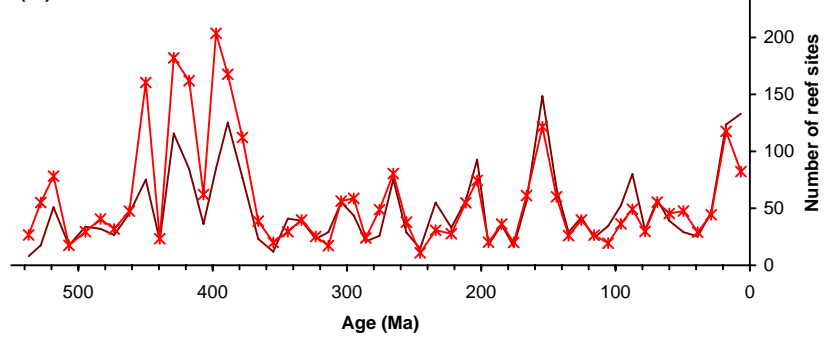

Fig. 4. Time series of the recorded number of non-oceanic, exposed reef sites without $\left(N_{\mathrm{O}}\right)$ and with adjustment for the GDP effect $\left(N_{\mathrm{GDP}}\right)$. The curves of $N_{\mathrm{O}}$ are the same as the curves of $N$ in Fig. 3. (a) Data resolved to supersequences. (b) Data resolved to $10 \mathrm{Myr}$ intervals (arrow marks late Anisian-Ladinian bin, see text for discussion). See the legend of Fig. 1 for additional information.

reasonable to assume that the bias on preserved reef carbonate production is proportional to the deviation from mean weathering rates. Unusually low rates will result in a positive departure from the exponential decay curve. Higher than normal weathering rates will result in a negative departure and an elevated decay constant. I used the chemical weathering rates derived by Berner and Kothavala (2001) from volumes of terrigenous rocks (Ronov, 1993). These values for siliciclastic rocks, are conservative estimates of carbonate weathering, which are usually much more prone to chemical weathering (Blum et al., 1998). The epic level chemical weathering rates $\left(f_{R}(t)\right)$ were interpolated and adjusted to the stratigraphic bins used herein. As the $f_{R}(t)$ values of Berner and Kothavala (2001) are already standardized to the Miocene level of chemical weathering, they can be directly applied to adjust the decay constants and achieve a corrected curve of reef volumes by using the following equation:

$(N, V)_{R}=(N, V)_{P} \times e^{k t f_{R}(t)}$

The effect of $f_{R}(t)$ is such that the decay constant at time $t$ is lowered when the intensity of chemical weathering is less than in the Miocene. Thereby the corrected values of $N$ and $V$ are lowered with respect to the simple correction for sedimentary decay. The opposite applies for bins in which chemical weathering is higher than during the Miocene.
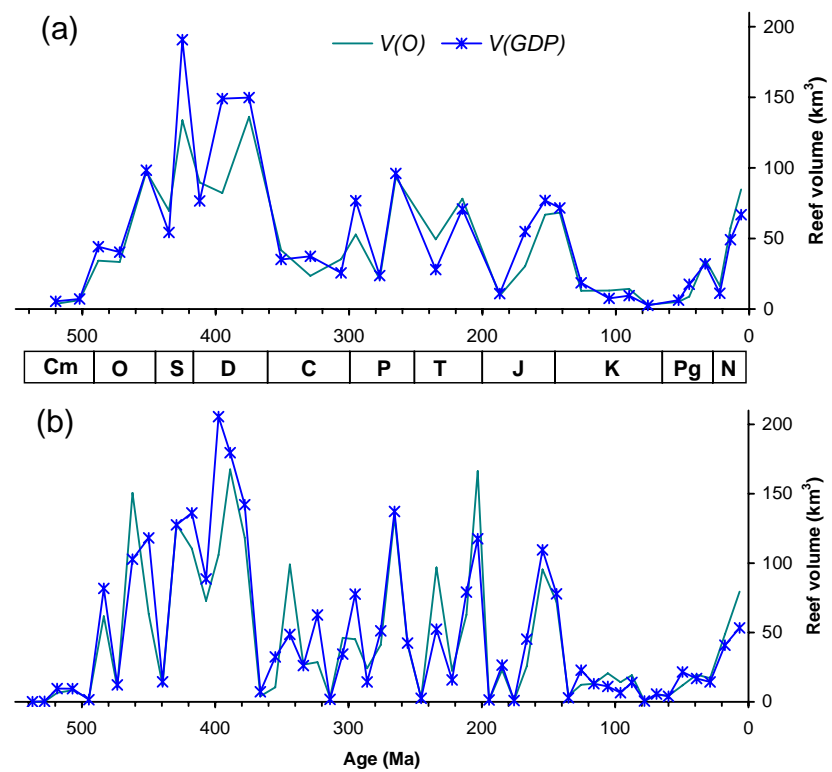

Fig. 5. Time series of the calculated non-oceanic, exposed reef volume without $\left(V_{\mathrm{O}}\right)$ and with adjustment for the GDP effect $\left(V_{\mathrm{GDP}}\right)$. The curves of $V_{\mathrm{O}}$ are the same as the curves of $V$ in Fig. 3. (a) Data resolved to supersequences. (b) Data resolved to $10 \mathrm{Myr}$ intervals (arrow marks late Anisian-Ladinian bin, see text for discussion). See the legend of Fig. 1 for additional information.

\section{Results}

The various levels of adjustment have a quite different impact on the observed curves on $N$ and $V$. The effect of removing oceanic reefs results in a minor modification of the original pattern (Fig. 2). Noticeable changes are limited to the Cretaceous and Cenozoic. A significant decline is observable especially in the Early Cretaceous and Neogene, due to the high proportion of reefs on oceanic atolls and seamounts in these intervals (see Sect. 2.1). The additional exclusion of subsurface reefs results in a visibly modified pattern (Fig. 3). Major peaks are often reduced, whereas the depressions in the raw data are usually little affected by the exclusion of subsurface reefs. As expected, the effects on $V$ are much stronger than on $N$, owing to the larger size of subsurface reefs (see Sect. 2.2). The most notable changes are visible in the Devonian and Neogene, which are times of especially intense subsurface exploration due to the high reservoir potential of reefs (Kiessling et al., 1999). Another interesting feature is the much more prominent peak in the latest Triassic, especially at the $10 \mathrm{Myr}$ sample resolution. This is explained by the fact that nearly all late Norian and Rhaetian reefs are known from exposures. The overall volatility of all time series is reduced, albeit not strongly (Table 4). Apart from this, the major times of reef growth are basically the same as in the raw data (Fig. 1), although the ranking has changed. 
Table 4. Standard deviations (std) and volatility (volat) of time series (volat was calculated according to Eq. 1). $N$ : number of reef sites; $V$ : reef volume $\left(\mathrm{km}^{3}\right)$.

\begin{tabular}{lccccc}
\hline & & \multicolumn{3}{c}{ Supersequences } & \multicolumn{2}{c}{$10 \mathrm{Myr}$ intervals } \\
& & $N$ & $V$ & $N$ & $V$ \\
\hline Raw data & std & 50.0 & 123.1 & 45.9 & 112.2 \\
& volat & 0.67 & 0.94 & 0.81 & 2.16 \\
Oceanic reefs excluded & std & 46.0 & 112.7 & 43.2 & 105.4 \\
& volat & 0.68 & 1.02 & 0.80 & 2.09 \\
Oceanic and subsurface reef excluded & std & 32.3 & 37.9 & 33.1 & 47.2 \\
& volat & 0.62 & 0.93 & 0.77 & 1.91 \\
GDP-adjusted data & std & 65.3 & 45.57 & 45.4 & 51.1 \\
& volat & 0.67 & 1.02 & 0.79 & 1.99 \\
Adjusted for sedimentary cycling & std & 75.9 & 76.8 & 75.0 & 55.1 \\
& volat & 0.69 & 1.04 & 0.80 & 1.69 \\
\hline
\end{tabular}

The correction for GDP density has substantial effects, especially in the early Paleozoic (Figs. 4 and 5). The strong concentration of reefs in countries with a fairly low GDP density (such as Russia, central Asian states and Mongolia, Table 1) at that time renders it likely that there are many undetected (or unreported) reefs in these countries. The adjustments often result in substantial additions to the previous datasets. There is a disturbing peak in the Wenlockian supersequence (S7, roughly at $425 \mathrm{Ma}$ ) after GDP-adjustment, which is visible both for $N$ (Fig. 4a) and $V$ (Fig. 5a). The peak, already present in the raw data, is enhanced due to the large number of reefs recorded from Canada, Russia and Mongolia, which have high correction factors (Table 1). As $N$ per unit area is more strongly controlled by GDP density than the cumulative reef volume, the GDP-adjusted curves of $N$ (Fig. 4) differ most strongly from the previous curves. The original values are more than doubled in several bins and usually raised by around $50 \%$ in the Paleozoic. For $V$, the GDP adjustments are usually much less pronounced (Fig. 5), with a maximum of +80 to $+90 \%$ in the Emsian-Eifelian supersequence (at $398 \mathrm{Ma}$ ), when several reefs are recorded from Mongolia, the country with the lowest GDP density in the analysis.

With few exceptions, the direction of changes is the same for $N$ and $V$. One notable exception is the Late Jurassic reef bloom (at around $155 \mathrm{Ma}$ ), which is interpreted to be overestimated by the analysis based on numbers, whereas in the volume analyses the original values are raised. This is due to the concentration of recorded reef sites in countries with a high GDP density (France, Germany, Slovenia) and the few reefs with large estimated volume being in countries with a low GDP density (Russia and Uzbekistan). The overall volatility in the time series is raised with respect to the previous adjustment level and is close to the volatility of the raw data (Table 4).

Reductions of the raw values are common in the Mesozoic and Cenozoic owing to concentrations of reefs in coun- tries with a relatively high GDP density. Occasionally, reductions are also observed in the Paleozoic (e.g., $V$ in the late Visean, because there are many records of reefs in the United Kingdom). A noteworthy reduction is seen in the second ten Myr bin of the Triassic (late Anisian-Ladinian) both for $N$ (Fig. 4b) and $V$ (Fig. 5b). Although not very distinct in absolute numbers, the proportional loss by GDPadjustment is significant (39\% and $46 \%$, respectively). This suggests that the relatively rapid recovery of reefs after the Permian-Triassic mass extinction may be overestimated due to observations in countries with a high GDP density (in this case Austria and Italy, the common reefs in China have little effect, because China's GDP density is close to average).

The final adjustment steps (sediment cycling) consistently intensify the early Paleozoic reef bloom. For supersequences, the Silurian peak now becomes extremely pronounced (Figs. 6a and 7a). At the finer stratigraphic resolution (Figs. 6b and 7b) the (middle and Late) Silurian is also identified as a major time of Phanerozoic reef expansion, but does not stand out against the peaks in the latest Ordovician and Emsian to Givetian ages. Except for volumes at the $10 \mathrm{Myr}$ sample resolution, this step of adjustment results in further increases of volatility (Table 4).

The overall similarity of the original and adjusted curves is greater than discernible at first glance (Fig. 8). The correlation between two subsequent levels of adjustment varies between 0.47 and 0.95 with generally higher similarities between time series of $N$ than between time series of $V$. There even is a surprisingly great similarity between the raw data and the final step of adjustment. It is only for reef volumes at the supersequence level where this similarity in not significant $(R=0.28, P=0.12)$. The patterns of changes (the differences between bins) in both $N$ and $V$ are even less affected by the adjustments. Although the magnitude of changes between adjacent time intervals varies considerably, the direction of change is hardly affected. Detrended time series (first differences) thus have a highly significant cross-correlation 


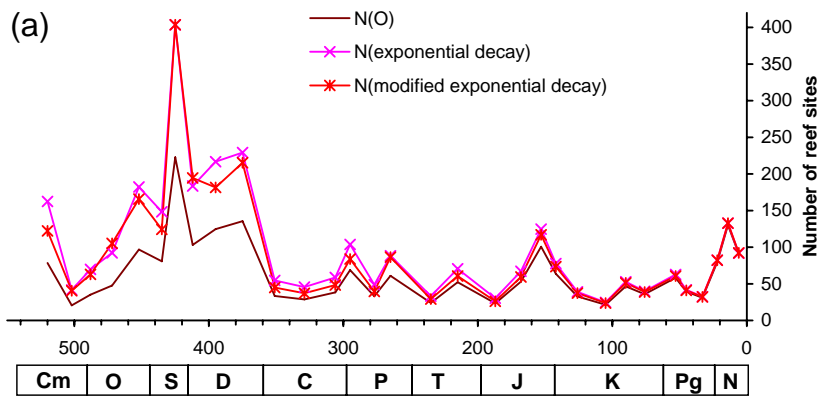

(b)

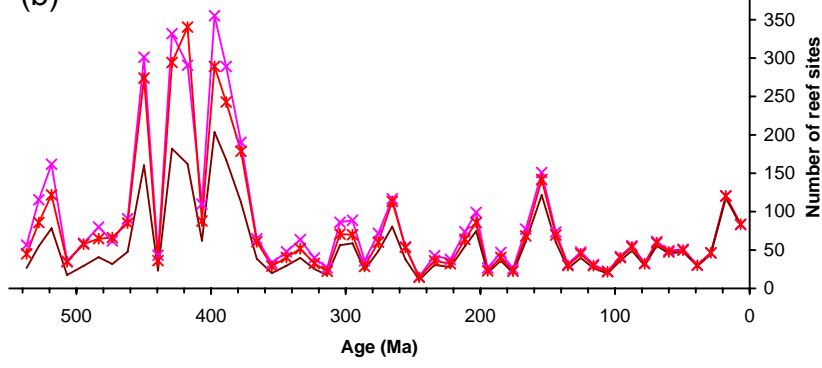

Fig. 6. Time series of the number of GDP-adjusted, non-oceanic, exposed reef sites adjusted for sedimentary decay. The curves of $N_{\mathrm{O}}$ are the same as the curves of $N_{\mathrm{GDP}}$ in Fig. 4 . The curves of $N$ (exponential decay) refer to a simple decay function as in Eq. (7), whereas the curves of $N$ (modified exponential decay) refer to a variable decay as in Eq. (8). (a) Data resolved to supersequences. (b) Data resolved to $10 \mathrm{Myr}$ intervals. See the legend of Fig. 1 for additional information.

Table 5. Cross-correlations $(R)$ between detrended time series of raw data and detrended time series (first differences) after final level of adjustment. $d f$ : degrees of freedom.

\begin{tabular}{ccccc}
\hline & \multicolumn{2}{c}{ Supersequences } & \multicolumn{2}{c}{$10 \mathrm{Myr}$ intervals } \\
& $N$ & $V$ & $N$ & $V$ \\
\hline$R$ & 0.82 & 0.56 & 0.70 & 0.69 \\
$d f$ & 30 & 30 & 51 & 51 \\
$P$ & $<0.001$ & $<0.001$ & $<0.001$ & $<0.001$
\end{tabular}

for all time series and between all levels of adjustments (Table 5). The basic pattern of waxing and waning in the reef ecosystem seen in the raw data is still observed in the adjusted curves.

\section{Discussion and conclusions}

The adjustments to the original time series of Phanerozoic reef abundance and volume are just first steps towards a reliable estimate of true fluctuations and they still have some shortcomings. As previously discussed (see Sects. 2.1 and 2.2 ), the exclusion of oceanic and subsurface reefs is not without problems, although these steps certainly remove
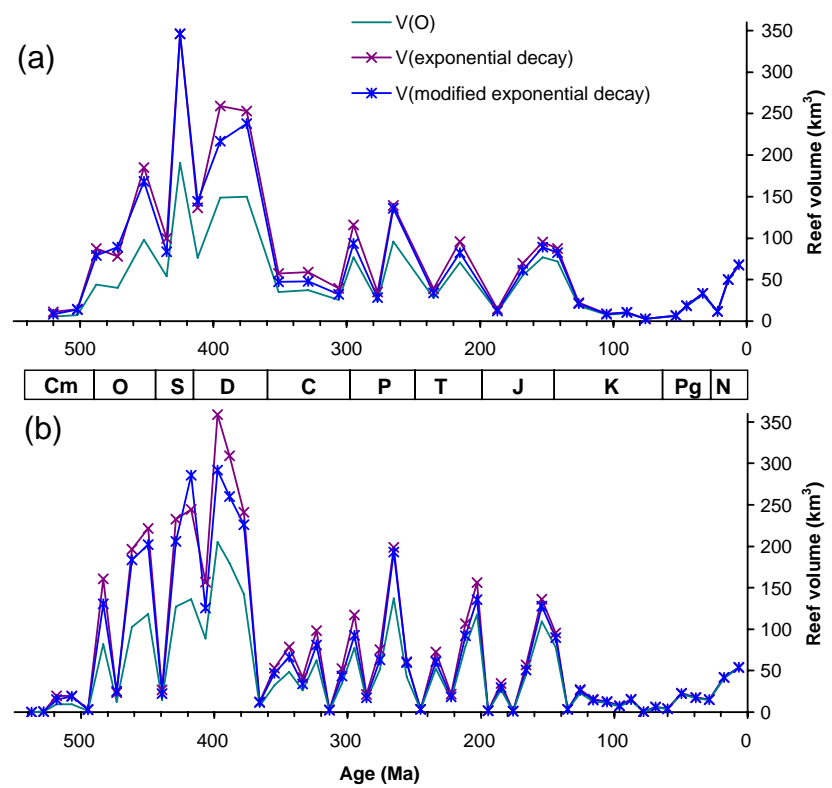

Fig. 7. Time series of GDP-adjusted, non-oceanic, exposed reef volumes adjusted for sedimentary decay. The curves of $V_{\mathrm{O}}$ are the same as the curves of $V_{\mathrm{GDP}}$ in Fig. 5. The curves of $V$ (exponential decay) refer to a simple decay function as in Eq. (7), whereas the curves of $V$ (modified exponential decay) refer to a variable decay as in Eq. (8). (a) Data resolved to supersequences. (b) Data resolved to $10 \mathrm{Myr}$ intervals. See the legend of Fig. 1 for additional information.

more bias than they add. Despite the use of a conservative approach, the adjustment for GDP density is perhaps exaggerated, because it applies the same correction factors for $N$ and $V$ to the same countries for all time intervals, irrespective of regional variations in geological characteristics. Due to low sample sizes, especially in some of the $10 \mathrm{Myr}$ intervals, the effect of the adjustment is probably too strong, albeit mathematically correct. One detailed survey in a country with a low GDP density (perhaps by scientists from another country) can substantially inflate the adjusted values. Problems are also involved in the effects of sedimentary cycling processes. I have applied the same decay constant for reef numbers and reef volumes, although the decay constant derived from the mass-age distribution of sedimentary rocks should only be applied to volumes. Additionally, I have applied variations in chemical weathering intensity of siliciclastic rocks to modify the exponential decay function, although carbonates are somewhat different in their weathering behavior (Bluth and Kump, 1994).

Given all these restrictions, how confident can we be about the final curves? One referee suggested to bolster the results by comparing the new time series with data of environmental changes. However, the presence or absence of crosscorrelations with environmental parameters would neither prove nor disprove the validity of the new curves. It should 

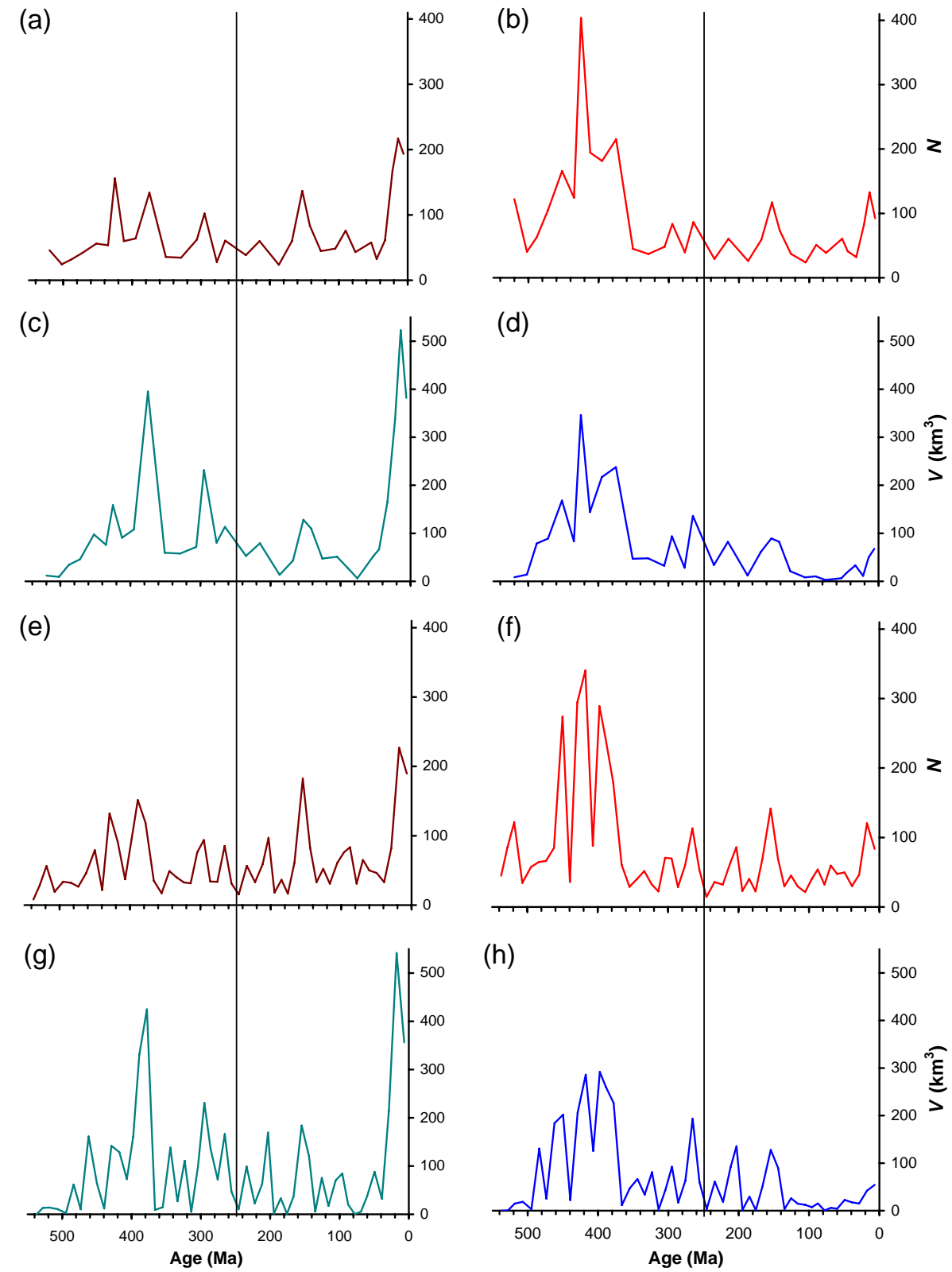

Fig. 8. Comparison of original time series (compare Fig. 1) and time series after all adjustments (compare Figs. 6 and 7). The four time series of $N$ and the four time series of $V$ are scaled to the same axis for an easier comparison. The Permian-Triassic boundary is marked by the thin vertical line for orientation. (a-d) Data resolved to supersequences; (a) original time series of reef abundance; (b) time series of reef abundance after adjustments; (c) original time series of reef volumes; (d) time series of reef volumes after adjustments. (e-h) Data resolved to $10 \mathrm{Myr}$ intervals; (e) original time series of reef abundance; (f) time series of reef abundance after adjustments; (g) original time series of reef volumes; (h) time series of reef volumes after adjustments.

be emphasized that cross-correlations between time series have to be performed based on detrended values (first or generalized differences; McKinney and Oyen, 1989) rather than on raw data, which are biased by autocorrelations. Therefore, the wiggles in the curves are more relevant than the general pattern for the assessment of extrinsic forcing. The fact that, after detrending, there is such a good cross-correlation be- tween raw curves and adjusted curves (Table 5), raises the credibility of both the original and the adjusted curves. At the same time this fact renders it unlikely that a repetition of previous analyses (Kiessling, 2002) with the new curves would yield different basic results. Perhaps, the waxing and waning of reefs is just not as directly (or linearly) controlled by environmental change as commonly thought. One additional 
observation may substantiate the trustworthiness of the new curves in favor of the originals: the general pattern of a much more productive reef factory in the Paleozoic than in the Mesozoic and Cenozoic is in line with global data on cratonic carbonates (Walker et al., 2002), whereas the original curves show a unlikely strong peak in the Neogene.

Although it is currently difficult to evaluate the errors in the new curves in detail, the methods presented here certainly show the correct basic steps towards "unbiasing" the fossil and geological records. Further constraints on (1) true fluctuations in the proportions of oceanic reefs relative to continental reefs through time, (2) exposed versus buried reefs and carbonate sediments (3) the GDP-density effect, (4) the decay constant for both reef numbers and volumes, and (5) changes in carbonate weathering intensity will permit to finetune the unbiased time series of Phanerozoic reef $\mathrm{CaCO}_{3}$ production. Future refinements, however, are unlikely to modify the conclusions that can be drawn from the current results:

1. Fluctuations in Phanerozoic reef proliferation were indeed profound. All adjustments failed to substantially reduce volatility in the dataset suggesting that the great fluctuations already seen in the raw data are real and of biological significance. Time series of reef volumes show greater volatility than time series of reef numbers (Table 4) suggesting that smaller reefs may behave differently from larger reefs.

2. The most prolific reef growth of the Phanerozoic was in the early Paleozoic and probably in the Silurian period. The result of an unparalleled reef bloom in the early Paleozoic is surprising and counter-intuitive given the common perception of the Cenozoic or even Neogene as the age of modern coral reefs (Veron, 1995; Perrin, 2002). However, there are previous qualitative statements of a maximum reef expansion in the Silurian and Devonian periods with reef areas up to 10 times the ones in the modern ocean (Copper, 1994), and, as stated above, the general pattern is more in line with quantifications of overall cratonic carbonate sedimentation (Walker et al., 2002).

My results have more general implications, because they are also applicable to other ecosystems, sedimentary units and estimates of biomass. To mention just a few examples, one could think of rainforests, radiolarites or the skeletal mass of shelly invertebrates as future applications of the methods presented here.

Acknowledgements. I thank M. Kowalewski and two anonymous reviewers for comments on the manuscript and J.-P. Gattuso for editorial handling.

Edited by: J.-P. Gattuso

\section{References}

Alroy, J., Marshall, C. R., Bambach, R. K., Bezusko, K., Foote, M., Fürsich, F. T., Hansen, T. A., Holland, S. M., Ivany, L. C., Jablonski, D., Jacobs, D. K., Jones, D. C., Kosnik, M. A., Lidgard, S., Low, S., Miller, A. I., Novack-Gottshall, P. M., Olszewski, T. D., Patzkowsky, M. E., Raup, D. M., Roy, K., Sepkoski Jr., J. J., Sommers, M. G., Wagner, P. J., and Webber, A.: Effects of sampling standardization on estimates of Phanerozoic marine diversification, Proceedings of the National Academy of Sciences (USA), 98, 6261-6266, 2001.

Antonellini, M. and Mollema, P. N.: A natural analog for a fractured and faulted reservoir in dolomite: Triassic Sella Group, Northern Italy, AAPG Bulletin, 84, 314-344, 2000.

Behn, M. D., Sinton, J. M., and Detrick, R. S.: Effect of the Galapagos hotspot on seafloor volcanism along the Galapagos Spreading Center (90.9-97.6 $\left.{ }^{\circ} \mathrm{W}\right)$, Earth and Planetary Science Letters, 217, 331-347, 2004.

Berner, R. A. and Kothavala, Z.: GEOCARB III: A revised model of atmospheric $\mathrm{CO} 2$ over phanerozoic time, American Journal of Science, 301, 182-204, 2001.

Blum, J. D., Gazis, C. A., Jacobson, A. D., and Chamberlain, C. P.: Carbonate versus silicate weathering in the Raikhot Watershed within the High Himalayan Crystalline Series, Geology, 26, 411414, 1998.

Bluth, G. J. S. and Kump, L. R.: Lithologic and climatologic controls of river chemistry, Geochim. Cosmochim. Acta, 58, 23412359, 1994.

Budyko, M. J., Ronov, A. B., and Yanshin, A. L.: History of the Earth's atmosphere, Springer, New York, 139 p., 1987.

Bush, A. M., Markey, M. J., and Marshall, C. R.: Removing bias from diversity curves: the effects of spatially organized biodiversity on sampling-standardization, Paleobiology, 30, 666-686, 2004.

Cloos, M.: Lithospheric buoyancy and collisional orogenesis: subduction of oceanic plateaus, continental margins, island arcs, spreading ridges, and seamounts, Geological Society of America Bulletin, 105, 715-737, 1993.

Copper, P.: Ancient reef ecosystem expansion and collapse. Coral Reefs, 13, 3-11, 1994.

Crampton, J. S., Beu, A. G., Cooper, R. A., Jones, C. M., Marshall, B., and Maxwell, P. A.: Estimating the rock volume bias in paleobiodiversity studies. Science, 301, 358-360, 2003.

Foote, M.: Inferring temporal patterns of preservation, origination, and extinction from taxonomic survivorship analysis, Paleobiology, 27, 602-630, 2001.

Gradstein, F., Ogg, J., and Smith, A.: A geologic time scale 2004, Cambridge University Press, Cambridge, pp. 589, 2004.

Gregor, C. B.: The mass-age distribution of Phanerozoic sediments, in: The Chronology of the Geologic Record, edited by: Snelling, N. J., Geological Society of America, Memoir, Boulder, 10, 284 289, 1985.

Hay, W. W. and Wold, C. N.: Relation of selected mineral deposits to the mass/age distribution of Phanerozoic sediments, Geologische Rundschau, 79, 495-512, 1990.

Kiessling, W.: Secular variations in the Phanerozoic reef ecosystem, in: Phanerozoic Reef Patterns, edited by: Kiessling, W., Flügel, E., and Golonka, J., SEPM Special Publications, Tulsa, 72, 625690, 2002. 
Kiessling, W.: Long-term relationships between ecological stability and biodiversity in Phanerozoic reefs, Nature, 433, 410-413, 2005a.

Kiessling, W.: Habitat effects and sampling bias on Phanerozoic reef distribution, Facies, 51, 24-32, 2005b.

Kiessling, W. and Flügel, E.: Paleoreefs - a database on Phanerozoic reefs, in: Phanerozoic Reef Patterns, edited by: Kiessling, W., Flügel, E., and Golonka, J., SEPM Special Publications, Tulsa, 72, 77-92, 2002.

Kiessling, W., Flügel, E., and Golonka, J.: Paleoreef maps: Evaluation of a comprehensive database on Phanerozoic reefs, AAPG Bulletin, 83, 1552-1587, 1999.

Kiessling, W., Flügel, E., and Golonka, J.: Fluctuations in the carbonate production of Phanerozoic reefs, in: Carbonate Platform Systems: components and interactions, edited by: Insalaco, E., Skelton, P. W., and Palmer, T. J., Geological Society Special Publication, London, 178, 191-215, 2000.

Kleypas, J. A.: Modeled estimates of global reef habitat and carbonate production since the last glacial maximum, Paleoceanography, 12, 533-545, 1997.

Larson, R. L.: Latest pulse of Earth: evidence for a mid-Cretaceous superplume, Geology, 19, 547-550, 1991.

Leinfelder, R. R., Werner, W., Nose, M., Schmid, D. U., Krautter, M., Laternser, M., Takacs, M., and Hartmann, D.: Paleoecology, growth parameters and dynamics of coral, sponge and microbolite reefs from the Late Jurassic, in: Global and regional controls on biogenic sedimentation, edited by: Reitner, J., Neuweiler, F., and Gunkel, F., Göttinger Arbeiten zur Geologie und Paläontologie, Göttingen, SB2, 227-248, 1996.

Mackenzie, F. T. and Morse, J. W.: Sedimentary carbonates through Phanerozoic time, Geochim. Cosmochim. Acta, 56, 3281-3295, 1992.

McKinney, M. L. and Oyen, C. W.: Causation and nonrandomness in biological and geological time series: temperature as a proximal control of extinction and diversity, Palaios, 4, 3-15, 1989.

Morse, J. W. and Mackenzie, F. T.: Geochemistry of Sedimentary Carbonates, Elsevier, Amsterdam, 707 p., 1990.

Perrin, C.: Tertiary: the emergence of modern reef ecosystems, in: Phanerozoic Reef Patterns, edited by: Kiessling, W., Flügel, E., and Golonka, J., SEPM Special Publications, Tulsa, 72, 587$621,2002$.
Peters, S. E. and Foote, M.: Biodiversity in the Phanerozoic: a reinterpretation, Paleobiology, 27, 583-601, 2001.

Ronov, A. B.: Stratisfera - Ili Osadochnaya Obolochka Zemli (Kolichestvennoe Issledovanie), Nauka, Moscow, 144 p., 1993.

Ronov, A. B.: Phanerozoic transgressions and regressions on the continents: a quantitative approach based on areas flooded by the sea and areas of marine and continental deposition, American Journal of Science, 294, 777-801, 1994.

Ronov, A. B., Khain, V. E., Balukhovsky, A. N., and Seslavinsky, K. B.: Quantitative analysis of Phanerozoic sedimentation, Sedimentary Geology, 23, 311-325, 1980.

Sestini, J.: Cenozoic stratigraphy and depositional history, Red Sea coast, Sudan, AAPG Bulletin, 49, 1453-1472, 1965.

Sloss, L. L.: Sequences in the cratonic interior of North America, Geological Society of America Bulletin, 74, 93-113, 1963.

Sloss, L. L.: Areas and volumes of cratonic sediments, western North America and eastern Europe, Geology, 4, 272-276, 1976.

Smith, A. B.: Large-scale heterogeneity of the fossil record: implications for Phanerozoic biodiversity studies, Philosophical Transactions of the Royal Society of London, B: Biological Sciences, 356, 351-367, 2001.

Stöcklin, L., Eftekhar-Nejad, J., and Hushmand-zadeh, A.: Geology of the Shotori Range (Tabas area, East Iran), Geological Survey of Iran, 3, 1-69, 1965.

Vecsei, A.: Database on isolated low-latitude carbonate banks, Facies, 43, 205-222, 2000.

Veron, J. E. M.: Corals in space and time, Cornell Press, Ithaca, 321 p., 1995.

Walker, L. J., Wilkinson, B. H., and Ivany, L. C.: Continental drift and Phanerozoic carbonate accumulation in shallow-shelf and deep-marine settings, J. Geology, 110, 75-87, 2002.

Wilkinson, B. H. and Walker, J. C. G.: Phanerozoic cycling of sedimentary carbonate. American Journal of Science, 289, 525-548, 1989.

Wilson, P. A., Jenkyns, H. C., Elderfield, H., and Larson, R. L.: The paradox of drowned carbonate platforms and the origin of Cretaceous Pacific guyots, Nature, 392, 889-894, 1998.

Wold, C. N. and Hay, W. W.: Estimating ancient sediment fluxes, American Journal of Science, 290, 1069-1089, 1990.

Wold, C. N. and Hay, W. W.: Reconstructing the age and lithology of eroded sediment, Geoinformatics, 4, 137-144, 1993. 